\title{
Polydatin inhibits the oxidative stress-induced proliferation of vascular smooth muscle cells by activating the eNOS/SIRT1 pathway
}

\author{
$\mathrm{YI} \mathrm{MA}^{1,2}, \mathrm{XUN} \mathrm{GONG}^{3}, \mathrm{YINGLI} \mathrm{MO}^{1}$ and SAIZHU WU ${ }^{1}$ \\ ${ }^{1}$ Department of Cardiology, Nanfang Hospital, Southern Medical University, Guangzhou, Guangdong 510515; \\ ${ }^{2}$ Department of Cardiology, The First Affiliated Hospital of Zunyi Medical College, Zunyi, Guizhou 563003; \\ ${ }^{3}$ Department of Cardiology, Changsha Central Hospital, Changsha, Hunan 410004, P.R. China
}

Received April 4, 2015; Accepted March 28, 2016

DOI: $10.3892 /$ ijmm.2016.2554

\begin{abstract}
Oxidative stress-mediated proliferation of vascular smooth muscle cells (VSMCs) contributes to plaque formation and the progression of atherosclerosis. Polydatin is a derivative of resveratrol, and is widely present in certain herbal medications used for the treatment of cardiovascular diseases. In the present study, we examined whether polydatin was capable of attenuating VSMC proliferation induced by oxidative stress as well as the potential involvement of the endothelial nitric oxide synthetase (eNOS)/SIRT1 pathway. Briefly, VSMCs were exposed to $\mathrm{H}_{2} \mathrm{O}_{2}$ for $24 \mathrm{~h}$ in the absence or presence of polydatin $(10-100 \mu \mathrm{M})$ prior to performing a cell proliferation assay. In mechanistic studies, the cells were incubated with the silent information regulator 1 (SIRT1) inhibitor, EX527, or the eNOS inhibitor, L-NAME, prior to polydatin treatment. The results showed that polydatin inhibited VSMC proliferation and the level of reactive oxygen species, increased the expression of Kip1/p27, SIRT1 and eNOS, whereas the expression of cyclin B1, Cdk1 and c-myc was decreased. The number of cells in the G2/M phase was increased. Pre-treatment with L-NAME attenuated the inhibitory effects of polydatin on cell proliferation, inhibited the expression of SIRT1 and the phosphorylation of eNOS. Pre-treatment with EX527 also attenuated the inhibitory effects of polydatin on cell proliferation, but failed to reduce the activation of eNOS and the production of nitric oxide. Taken together, these findings suggest that, polydatin inhibited the oxidative stress-induced proliferation of VMSCs by activating the eNOS/SIRT1 pathway.
\end{abstract}

Correspondence to: Dr Saizhu Wu, Department of Cardiology, Nanfang Hospital, Southern Medical University, 1838 North Guangzhou Avenue, Guangzhou, Guangdong 510515, P.R. China E-mail: wsznanfang1962@126.com

Key words: polydatin, vascular smooth muscle cell, proliferation, atherosclerosis, oxidative stress, signaling pathway

\section{Introduction}

Drinking wine in moderation, in particular red wine, may lower the incidence of cardiovascular diseases, presumably due in part to the benefits of resveratrol in the wine (1). Polydatin is a glycoside derivative of resveratrol, and widely present in various plant sources including red wine, grapes skins and Japanese knotweed (2). Polydatin is an ingredient of many herbal medications used for the treatment of cardiovascular diseases in China. Similar to resveratrol, polydatin has antioxidant (3), anti-inflammatory (4) and anti-ageing (5) effects.

It has been shown that oxidative stress promotes the proliferation of vascular smooth muscle cells (VSMCs) and induces blood vessel remodeling (6), thereby contributing to the pathogenesis of atherosclerosis $(7,8)$. Consequently, inhibiting VSMC proliferation may be used as a future therapeutic strategy for the treatment of atherosclerosis. Previous studies have indicated that polydatin may protect cardiac function from acute injury by reducing oxidative stress and inhibiting sarcoplasmic reticulum $\mathrm{Ca}^{2+}$ leakage (9), inhibiting platelet aggregation and intercellular cell adhesion molecule-1 (ICAM-1) expression, and weakening white blood cell-endothelial cell adhesion (10). However, the effect of polydatin on the oxidative stress-induced proliferation of VSMCs remains unclear.

Silent information regulator 1 (SIRT1) is a key factor that regulates cell responses to oxidative stress by deacetylating non-histone targets (11). Inhibiting SIRT1 expression has been demonstrated to accelerate cell senescence and promote cell injury $(12,13)$. Knockdown of SIRT1 by small interfering RNA in HUVECs resulted in impaired antioxidant ability (14). A previous study from this laboratory revealed that the expression of SIRT1 was reduced in ageing (15). The improvement of endothelial function in the thoracic artery of ageing rats by atorvastatin was associated with the increased expression of SIRT1 and endothelial nitric oxide synthase (eNOS) (15).

In the present study, we demonstrated that polydatin inhibited the oxidative stress-induced proliferation of VSMCs. We then examined the potential role of the eNOS/SIRT1 pathway with EX527, a SIRT1 inhibitor, and L-NAME, an eNOS inhibitor. 


\section{Materials and methods}

Cell culture. VSMCs were isolated from the thoracic aorta of 12-week-old male Sprague-Dawley rats (Experimental Animal Center, Southern Medical University, Guangzhou, China) as previously described (16). The present study was performed in strict accordance with the Guide for the Care and Use of Laboratory Animals (15). Experimental procedures were approved by the Animal Research Committee of Nanfang Hospital. The purity of the isolated VSMCs was verified using immunohistochemical staining of smooth muscle $\alpha$-actin. The cells were cultured in Dulbecco's modified Eagle's medium (DMEM; Gibco, Grand Island, NY, USA) containing $10 \%$ fetal bovine serum (FBS; PAA Laboratories $\mathrm{GmbH}$, Australia), in a humidified incubator containing 5\% $\mathrm{CO}_{2}$ at $37^{\circ} \mathrm{C}$. VSMCs at 4-6 passages, and at $40 \%$ confluence, were used for the experiments.

Treatment. In the preliminary dose-finding experiments, VSMCs were exposed to the vehicle (0.1\% DMSO) and $100 \mu \mathrm{M}$ $\mathrm{H}_{2} \mathrm{O}_{2}$ (Sigma-Aldrich, St.Louis, MO,USA) (14) in the absence or presence of polydatin (purity $\geq 98 \%$, HPLC) $(10,50$ or $100 \mu \mathrm{M}$; Baoji Herbest Bio-Tech Co., Ltd., Baoji, China) for $24 \mathrm{~h}$ prior to performing a cell proliferation assay using a CCK-8 assay kit (Beyotime Institute of Biotechnology, Nantong, China), as previously described (17). Absorbance was measured with an enzyme-linked microplate assay reader (Thermo Fisher Scientific, Waltham, MA, USA) at $450 \mathrm{~nm}$. In the subsequent set of experiments, the cells were treated with $100 \mu \mathrm{M}$ eNOS inhibitor L-NAME (18) or $10 \mu \mathrm{M}$ SIRT1 inhibitor EX527 (both from Sigma-Aldrich) (13) for $2 \mathrm{~h}$ prior to treatment with $\mathrm{H}_{2} \mathrm{O}_{2}$ and polydatin $(100 \mu \mathrm{M})$.

Measurement of reactive oxygen species (ROS), superoxide dismutase (SOD) and nitric oxide (NO) levels. Re-suspended cells were incubated in pre-warmed DMEM containing 2,7-dichlorofluorescein diacetate $\left(\mathrm{H}_{2}\right.$ DCFDA; Gibco) fluorescent probe $(5 \mu \mathrm{M})$ at $37^{\circ} \mathrm{C}$ for $30 \mathrm{~min}$. The cells were washed with PBS twice. Intracellular ROS was examined using a spectrofluorometer (Agilent Technologies, Inc., Palo Alto, CA, USA) at an excitation wavelength of $485 \mathrm{~nm}$ and an emission wavelength of $530 \mathrm{~nm}$, as previously described (19). A thiobarbituric acid method was used to detect SOD with WST-1 assay kit (Jiancheng Bioengineering Institute, Nanjing, China) (20). NO in the supernatant was examined using a Total Nitric Oxide Assay kit (Jiancheng Bioengineering Institute), as previously described (21). Since NO is rapidly converted to nitrite $\left(\mathrm{NO}_{2}^{-}\right)$and further to nitrate $\left(\mathrm{NO}_{3}^{-}\right)$, $\mathrm{NO}$ content was reflected by nitrite plus nitrate, as measured with Griess reagent.

Western blot analysis. Total protein was measured using a bicinchoninic acid (BCA) method. Samples containing $50 \mu \mathrm{g}$ protein were separated by $10 \%$ SDS-PAGE and transferred to PVDF membranes (Millipore, Bedford, MA, USA). The membranes were blocked with $5 \%$ non-fat milk in Tris-buffered saline containing $0.1 \%$ Tween-20 at room temperature for $1.5 \mathrm{~h}$, and then incubated overnight at $4^{\circ} \mathrm{C}$ with anti-Kip1/p27 antibody (1:500), anti-cyclin B1 antibody (1:500), anti-cyclin dependent kinase (Cdk)1 antibody
(1:500), anti-c-myc antibody $(1: 1,000)$, phosphorylated (p-) (Ser1177)-eNOS antibody (1:250), anti-eNOS antibody (1:250) or anti-SIRT antibody (1:500). Polyclonal primary antibodies against SIRT1, p-(Ser1177)-eNOS and eNOS were purchased from Cell Signaling Technology, Inc. (Boston, MA, USA) and Kip1/p27, cyclin B1, Cdk1 and c-myc were purchased from Santa Cruz Biotechnology, Inc. (Santa Cruz, CA, USA). Following incubation with a horseradish peroxidase (HRP)conjugated secondary antibody (Bio-Rad, Hercules, CA, USA) for $1 \mathrm{~h}$, the blots were visualized using an enhanced chemiluminescence (ECL) method. Bands of interest were quantified using Image $J$ software (National Institutes of Health, Bethesda, MD, USA). $\beta$-actin (1:1,000; ZSGB-BIO, Beijing, China) was used as the loading control.

Cell cycle analysis. The cells were fixed with ice-cold $70 \%$ ethanol for $4 \mathrm{~h}$, washed with PBS twice and stained with propidium iodide (PI). A minimum of $1 \times 10^{3}$ cells/sample were counted. Cells in distinct cell cycles were characterized by DNA amount (G0/G1 cells, diploid; S cells, DNA synthesis between diploid and tetraploid; and $\mathrm{G} 2 / \mathrm{M}$ cells, tetraploid) using flow cytometry (FCM; Beckman Coulter, Inc., Brea, CA, USA), as previously reported (22).

Reverse transcription quantitative-polymerase chain reaction $(R T-q P C R)$. Total RNA was extracted with RNAiso Plus (Takara Bio, Dalian, China) using a phenol-chloroform method. Reverse transcription was carried out in $20 \mu 1$ reaction mixture containing $1 \mu \mathrm{g}$ total RNA. The primers were designed using GenBank sequences and Primer-BLAST (Table I). The resulting cDNA was amplified using a SYBR-Green PCR method. Initial denaturation was performed at $94^{\circ} \mathrm{C}$ for $5 \mathrm{~min}$, followed by 40 cycles of denaturation at $94^{\circ} \mathrm{C}$ for $30 \mathrm{sec}$, annealing at $60^{\circ} \mathrm{C}$ for $30 \mathrm{sec}$ and extension at $72^{\circ} \mathrm{C}$ for $45 \mathrm{sec}$. SIRT1 and eNOS mRNA were calculated using a comparative threshold cycle $(\mathrm{Ct})$ method $(\Delta \Delta \mathrm{Ct}$ method) with $\beta$-actin as a reference.

Statistical methods. Data were presented as the means \pm standard deviation (SD) for at least three sets of independent experiments and analyzed using one-way analysis of variance (ANOVA), followed by post-hoc analysis for pairwise comparison: LSD method upon homogeneity of variance, Dunnett's t-test. $\mathrm{P}<0.05$ (two-sided test) was considered to indicate a statistically significant difference. Statistical analyses were performed using SPSS 13.0 software (SPSS Inc., Chicago, IL, USA).

\section{Results}

Effect of polydatin on proliferation. Polydatin attenuated $\mathrm{H}_{2} \mathrm{O}_{2}$-induced VSMC proliferation in a concentration-dependent manner $\left(\mathrm{P}<0.05\right.$ at 50 and $100 \mu \mathrm{M}$ vs. $\mathrm{H}_{2} \mathrm{O}_{2}$-treated group alone; Fig. 1A). Polydatin concentrations of 50 and $100 \mu \mathrm{M}$ were selected for subsequent experiments.

Effects of polydatin on ROS, SOD, NO, eNOS and SIRTI. At 50 and $100 \mu \mathrm{M}$, polydatin significantly decreased the level of ROS, and increased the activity of SOD and the level of $\mathrm{NO}\left(\mathrm{P}<0.05\right.$ vs. $\mathrm{H}_{2} \mathrm{O}_{2}$-treated group alone; Fig. 1B-D). 
Table I. Primers used for RT-qPCR.

\begin{tabular}{lll}
\hline Target mRNA & \multicolumn{1}{c}{ Forward primer (5' to $\left.3^{\prime}\right)$} & \multicolumn{1}{c}{ Reverse primer (5' to 3') } \\
\hline SIRT1 & ACAACCTCCTGTTGGCTGATGAGA & AGAATTGTTCGAGGATCGGTGCCA \\
eNOS & GGATCCAGTGGGGGAAACTG & TGGCTGAACGAAGATTGCCT \\
$\beta$-actin & CCCATCTATGAGGGTTACGC & TTTAATGTCACGCACGATTTC \\
\hline
\end{tabular}

SIRT1, silent information regulator 1; eNOS, endothelial nitric oxide synthase.
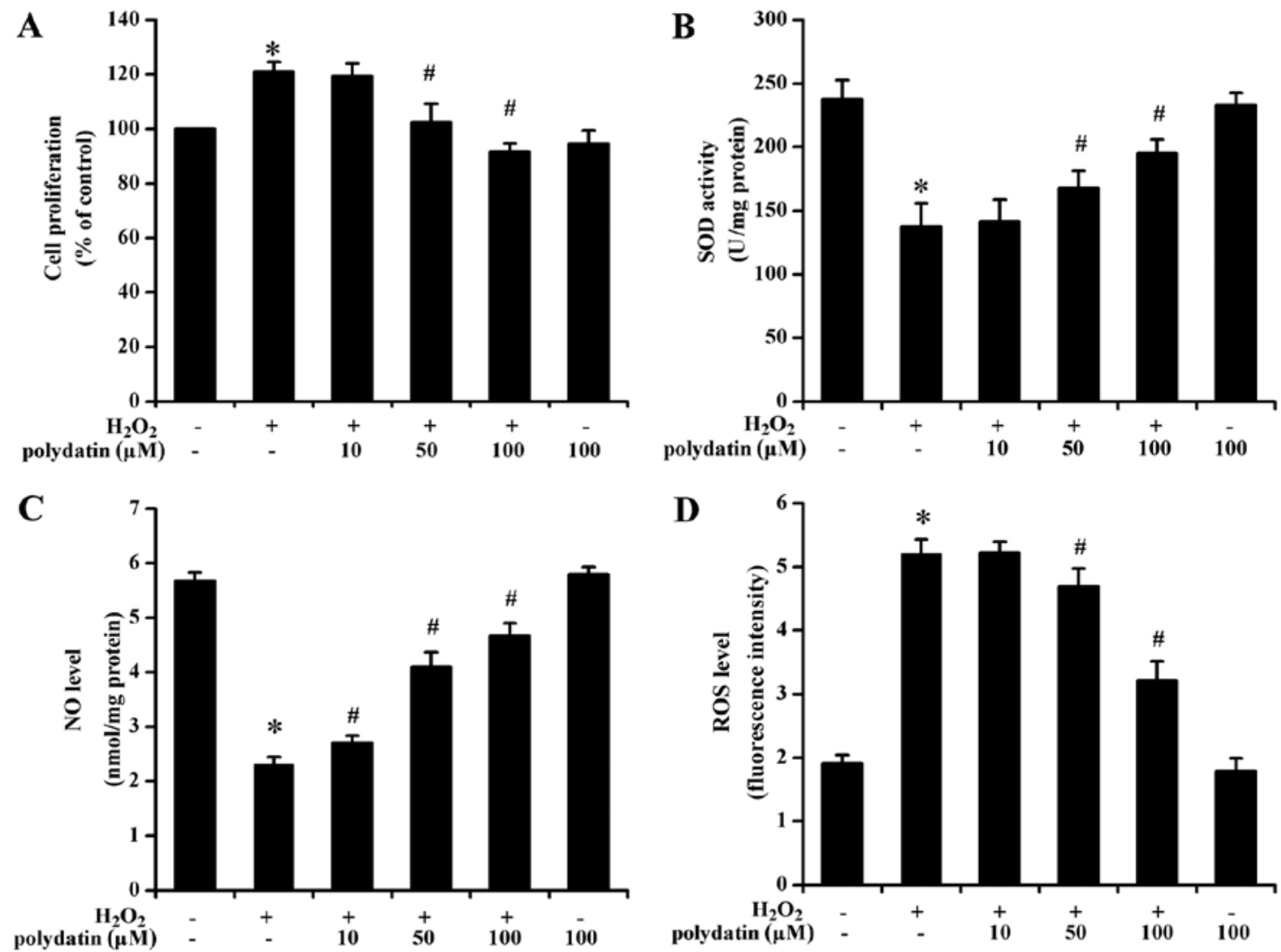

Figure 1. Effects of polydatin on vascular smooth muscle cells (VSMCs) under $\mathrm{H}_{2} \mathrm{O}_{2}$-induced oxidative stress. VSMCs were incubated with either vehicle (DMSO) or 10-100 $\mu \mathrm{M}$ polydatin in the presence of $\mathrm{H}_{2} \mathrm{O}_{2}(100 \mu \mathrm{M})$ for $24 \mathrm{~h}$. (A) Cell proliferation in different groups. (B) Superoxide dismutase (SOD) activity of VSMCs in different groups. (C) Nitric oxide (NO) level of VSMCs in different groups. (D) ROS level of VSMCs in different groups. Data are presented as the means $\pm \mathrm{SD} ; \mathrm{n}=5$ per group. ${ }^{\mathrm{P}}<0.05$ vs. control group; ${ }^{*} \mathrm{P}<0.05$ vs. $\mathrm{H}_{2} \mathrm{O}_{2}$-treated group alone.

Polydatin $(100 \mu \mathrm{M})$ increased the mRNA level of SIRT1 and eNOS in cells exposed to $\mathrm{H}_{2} \mathrm{O}_{2}(\mathrm{P}<0.05$ vs. $50 \mu \mathrm{M}$ polydatin-treated group; Fig. 2A and B). The results obtained with western blot analysis were generally consistent with the mRNA findings (Fig. 2C).

Effects of polydatin on the cell cycle. Treatment with polydatin increased the number of cells in the $\mathrm{G} 2 / \mathrm{M}$ phase (from $3.78 \pm 0.26$ to $15.62 \pm 0.22 \%$ and $23.31 \pm 0.34 \%$ at 50 and $100 \mu \mathrm{M}$, respectively) and decreased the number of cells in the G0/G1 phase (from $92.15 \pm 0.19$ to $77.02 \pm 0.31 \%$ and $66.30 \pm 0.18 \%$ at 50 and $100 \mu \mathrm{M}$, respectively) $\left(\mathrm{P}<0.05\right.$ at 50 and $100 \mu \mathrm{M}$ vs. $\mathrm{H}_{2} \mathrm{O}_{2}-$ treated group alone; Fig. 3).

Effects of polydatin on the cell cycle proteins. $\mathrm{H}_{2} \mathrm{O}_{2}$ treatment alone increased cyclin $\mathrm{B} 1$ and $\mathrm{Cdk} 1$ and decreased
Kip1/p27 ( $\mathrm{P}<0.05$ vs. the control group; Fig. 4A). Polydatin decreased cyclin $\mathrm{B} 1$ and $\mathrm{Cdk} 1$ expression and increased $\mathrm{Kip} 1 / \mathrm{p} 27$ expression in cells exposed to $\mathrm{H}_{2} \mathrm{O}_{2}(\mathrm{P}<0.05$ vs. the $\mathrm{H}_{2} \mathrm{O}_{2}$-treated group alone). $\mathrm{H}_{2} \mathrm{O}_{2}$ increased the protein level of c-myc. Polydatin inhibited such a response ( $\mathrm{P}<0.05$ vs. the $\mathrm{H}_{2} \mathrm{O}_{2}$-treated group alone; Fig. 4B).

Effects of L-NAME and EX527 pre-treatment. The CCK-8 assay revealed that polydatin inhibited VSMC proliferation (Fig. 5A). L-NAME pre-treatment reversed the effects of polydatin on SOD activity (Fig. 5B) and ROS levels (Fig. 5D). Additionally, L-NAME pre-treatment decreased NO levels (Fig. 5C). Polydatin $(100 \mu \mathrm{M})$ increased the phosphorylation of eNOS protein (p-eNOS) at Ser1177 of its catalytic subunit, and L-NAME treatment attenuated such a response $(\mathrm{P}<0.05$; Fig. 5E). 
A

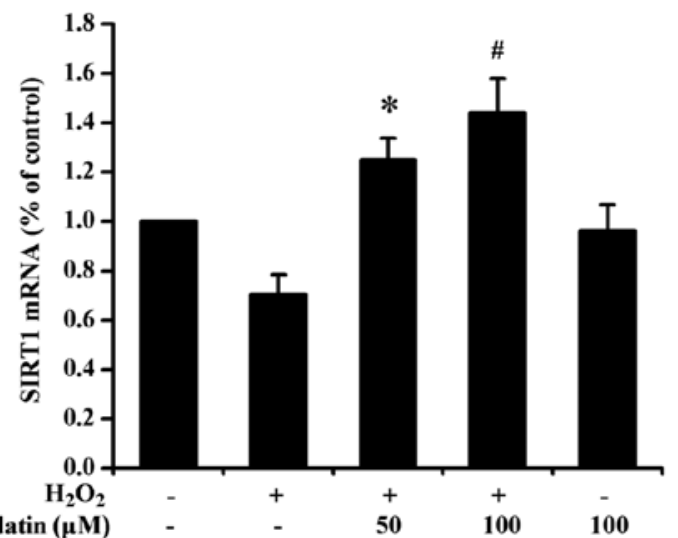

C SIRT1

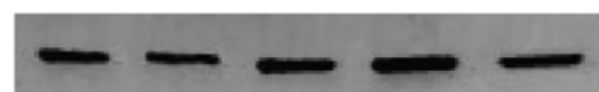

eNOS

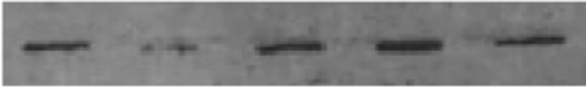

$\beta$-actin

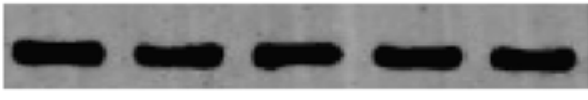

$\mathrm{H}_{2} \mathrm{O}_{2}$

polydatin $(\mu \mathrm{M})$

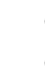

100
B

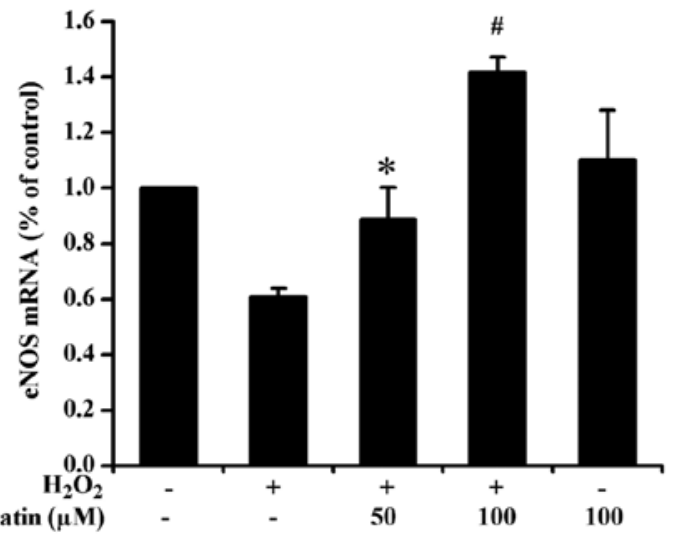

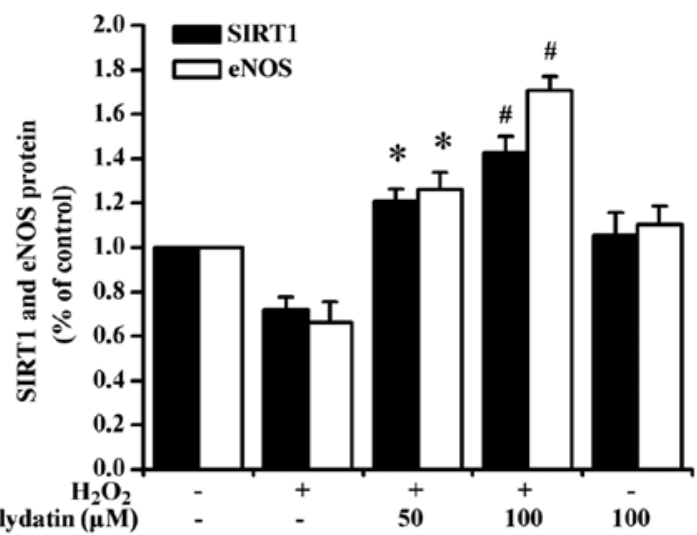

Figure 2. Effects of polydatin on the mRNA level and protein expression of silent information regulator 1 (SIRT1) and eNOS. (A) Measurement of SIRT1 mRNA level in different groups. (B) Measurement of eNOS mRNA level in different groups. (C) Measurement of SIRT1 and eNOS protein expression in different groups. Data are presented as the means $\pm \mathrm{SD} ; \mathrm{n}=3$ per group. ${ }^{*} \mathrm{P}<0.05$ vs. $\mathrm{H}_{2} \mathrm{O}_{2}$-treated group alone; ${ }^{\prime \prime} \mathrm{P}<0.05$ vs. $\mathrm{H}_{2} \mathrm{O}_{2}$ combined with $50 \mu \mathrm{M}$ polydatin treatment group.
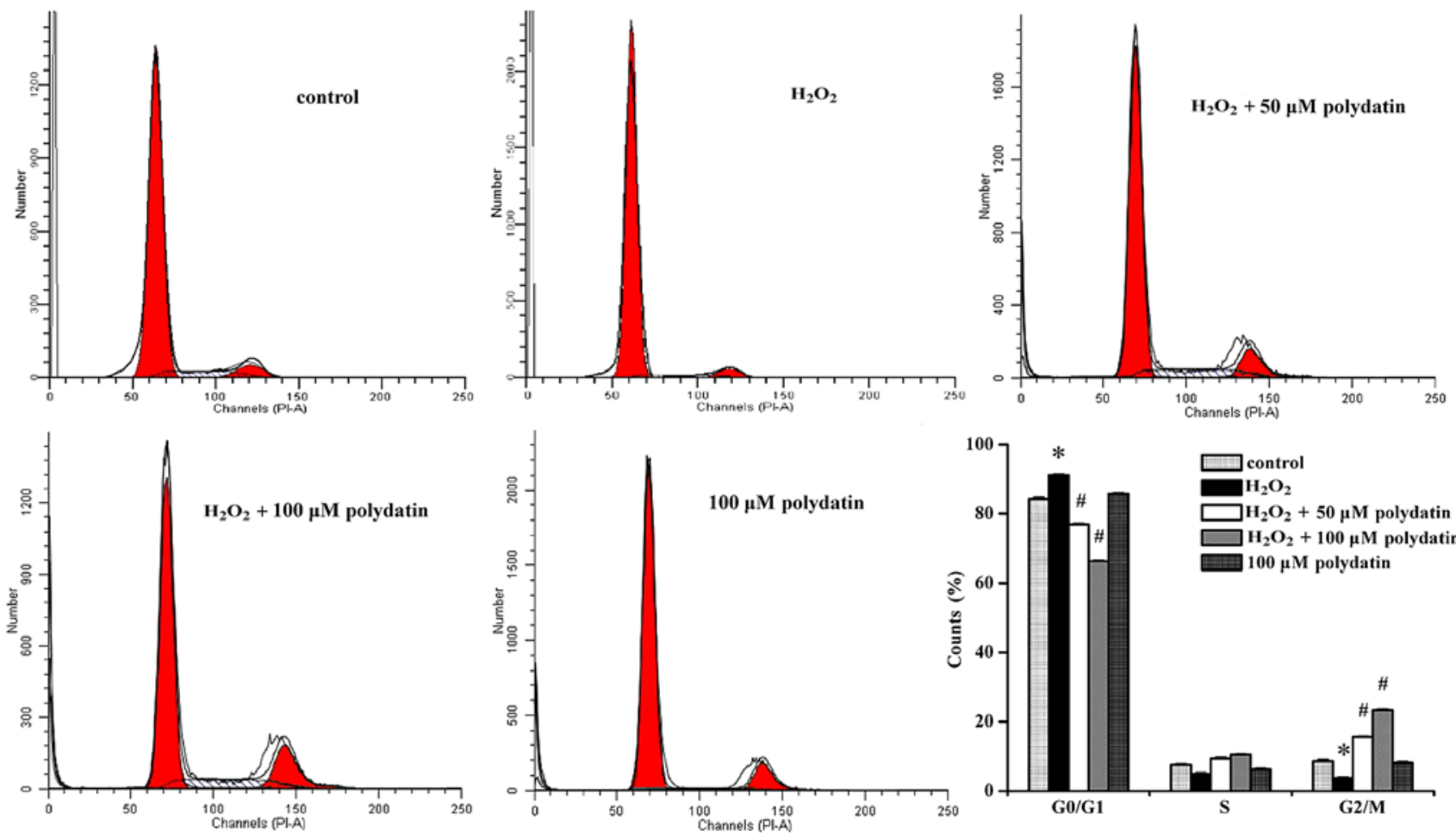

Figure 3. Effects of polydatin on the cell cycle of vascular smooth muscle cells (VSMCs) in the presence of $\mathrm{H}_{2} \mathrm{O}_{2}$. Cells were co-treated with different concentrations of polydatin $(50$ and $100 \mu \mathrm{M})$ and $\mathrm{H}_{2} \mathrm{O}_{2}$ or vehicle-treated control for $24 \mathrm{~h}$. Cell cycle analysis was then performed by measuring the cellular DNA content. Data are presented as the means $\pm \mathrm{SD} ; \mathrm{n}=3$ per group. " $\mathrm{P}<0.05$ vs. control group; ${ }^{*} \mathrm{P}<0.05$ vs. $\mathrm{H}_{2} \mathrm{O}_{2}$-treated group alone. 


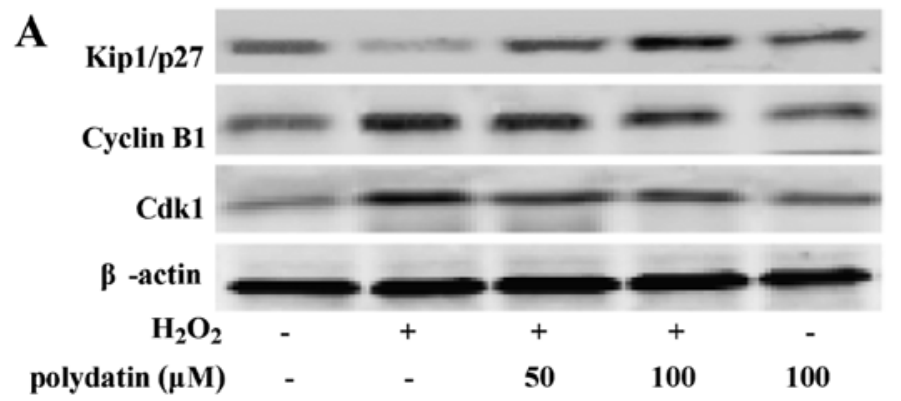

B
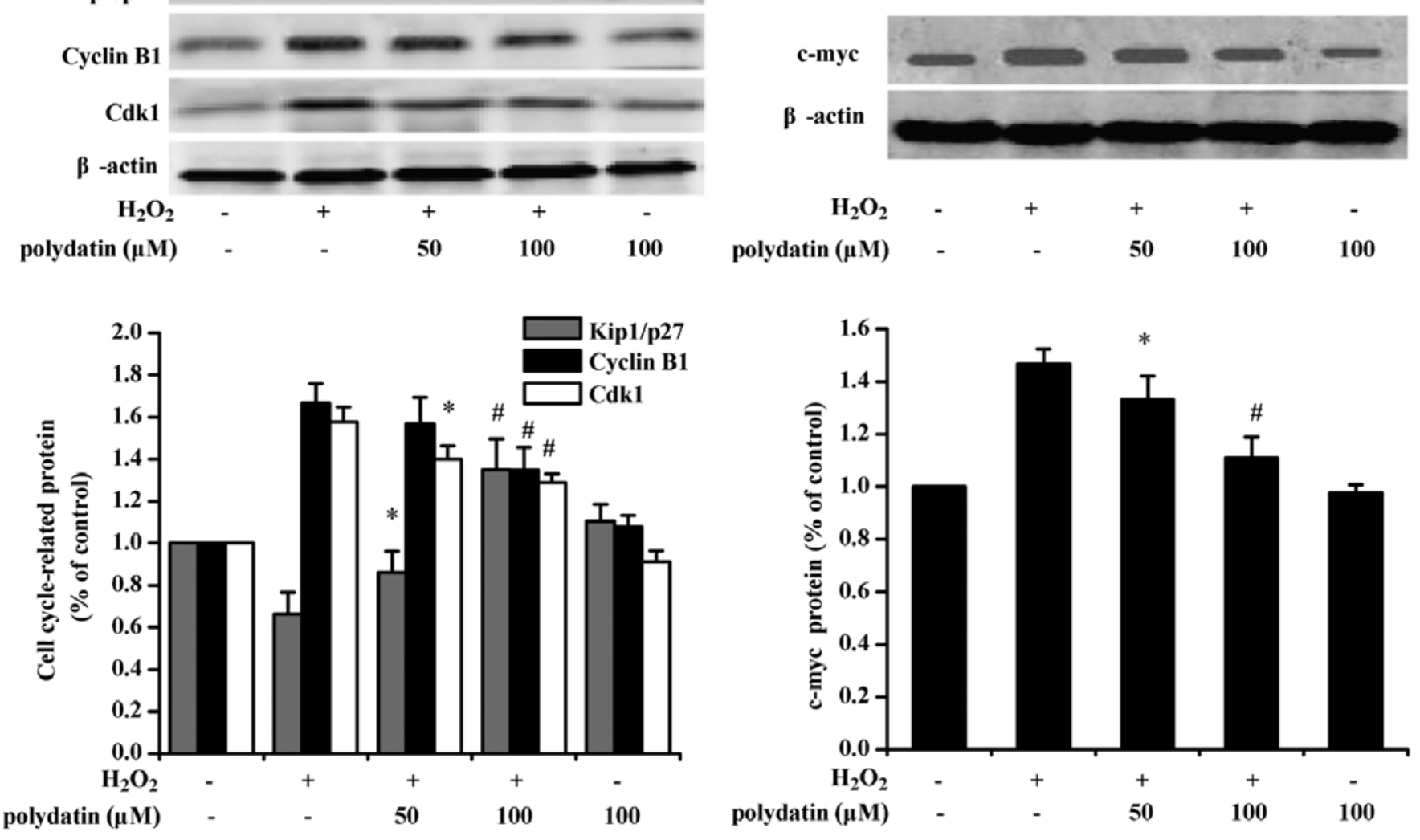

Figure 4. Effects of polydatin on cell cycle-related protein levels in the presence of $\mathrm{H}_{2} \mathrm{O}_{2}$. (A) Kip1/p27, cyclin B1 and Cdk1. (B) c-myc. The total cellular lysis products for protein extraction were prepared and adjusted for western blot analysis with proper dilutions of specific antibodies for Kip1/p27, cyclin B1, Cdk1, c-myc and $\beta$-actin. Data are presented as the means $\pm \mathrm{SD} ; \mathrm{n}=3$ per group. ${ }^{*} \mathrm{P}<0.05$ vs. $\mathrm{H}_{2} \mathrm{O}_{2}$-treated group alone; ${ }^{*} \mathrm{P}<0.05$ vs. $\mathrm{H}_{2} \mathrm{O}_{2}$ combined with $50 \mu \mathrm{M}$ polydatin treatment group.

EX527 pre-treatment attenuated the anti-proliferative effects of polydatin (Fig. 6A). EX527 pre-treatment also decreased SOD activity (Fig. 6B) and increased ROS levels (Fig. 6D). EX527 pre-treatment significantly decreased SIRT1 expression at the protein level $(\mathrm{P}<0.05)$. There was no decrease in NO levels (Fig. 6C), and eNOS and p-eNOS expression at the protein level (Fig. 6E). L-NAME and EX527 pre-treatment decreased the expression of Kip1/p27 at the protein level, and increased cyclin B1 (Fig. 7).

\section{Discussion}

The results from the present study have shown that polydatin, an analog of resveratrol, attenuated the proliferation of VSMCs under oxidative stress. Such an effect may be attributed to G2/M-phase arrest, an increased antioxidant capacity, and activation of the eNOS-SIRT1 signaling pathway in the VSMCs.

Resveratrol has been previously reported to have antiproliferative (23), antioxidant (24) and anti-aging $(25,26)$ properties in vitro and in vivo. Polydatin, also known as piceid, is a derivative of resveratrol. Polydatin and resveratrol have been demonstrated to produce their effects via the stilbene synthesis pathway (27). Previous studies have indicated that stilbene derivatives with more phenolic moieties and an increased number of $\mathrm{OH}$ groups on the phenol ring have improved biological effects compared with resveratrol (28), including lower toxicity, better anticancer activities and sirtuin activation (29). Hydroxystilbene analogues with more hydroxyl groups on the phenol rings of the stilbene structure tend to have higher anti-radical activity than resveratrol (29). Polydatin has more potent anti-proliferative effects on intestinal epithelial cells than resveratrol (30), possibly due to an increased number of hydroxyl groups on the ring-structure.

Cell proliferation is accompanied by the activation of cell cycle proteins (31). The cell cycle is controlled by many factors, including cyclins/CDK complexes and CDK inhibitors (CDKI) (32). High activity of the cyclin B1/CDK complex allows the progression of cells through the G2/M phase, and thus, is critical for mitosis (33). Previous findings have shown that resveratrol inhibited VSMC proliferation by inducing cell cycle arrest and increasing DNA synthesis (22). The results from the present study indicated that the promotion of VSMC proliferation by oxidative stress was accompanied by an increased expression of cyclin B1 and Cdk1, and a decreased expression of Kip1/p27 (Fig. 4). A previous study indicated that the downregulation of CDKI and Kip1/p27, interfered with G2/M arrest in response to DNA injury stress, thereby increasing genetic instability (34). Consistent with those findings, our data indicated that polydatin 

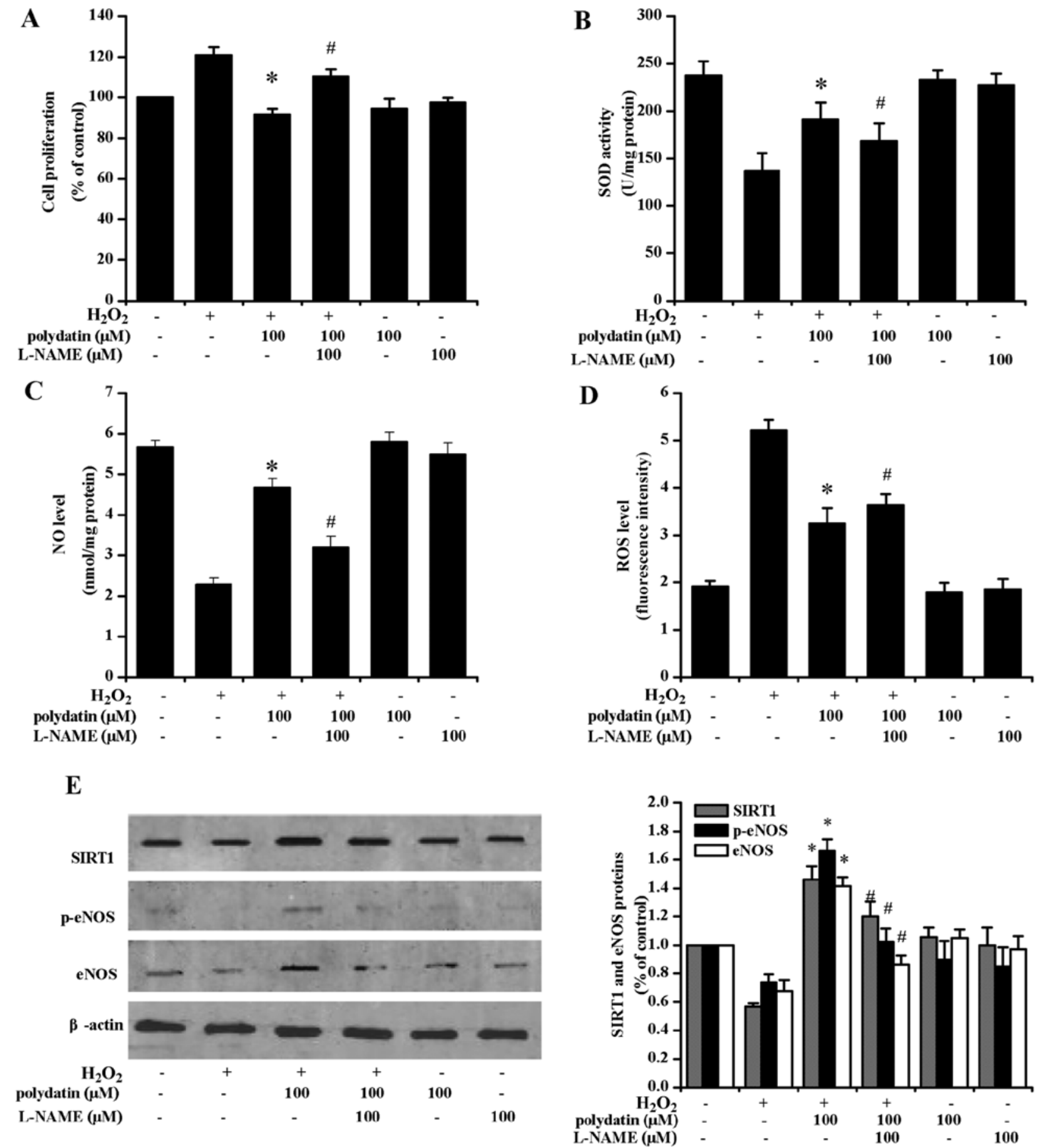

Figure 5. Effects of L-NAME in vascular smooth muscle cells (VSMCs). (A) Measurement of cell proliferation in VSMCs treated with L-NAME. (B) Measurement of SOD activity in different groups. (C) Measurement of NO levels in different groups. (D) Measurement of ROS levels in different groups. (E) Quantification of silent information regulator 1 (SIRT1), p-eNOS and eNOS protein expression in different groups detected by western blot analysis. Data are presented as the means $\pm \mathrm{SD}$ of three independent experiments. ${ }^{*} \mathrm{P}<0.05$ vs. $\mathrm{H}_{2} \mathrm{O}_{2}$-treated group alone; ${ }^{\#} \mathrm{P}<0.05$ vs. $\mathrm{H}_{2} \mathrm{O}_{2}$ combined with $100 \mu \mathrm{M}$ polydatin treatment group.

inhibited oxidative stress-induced VSMC proliferation, in part by arresting the cell cycle at the G2/M phase (Fig. 3). This finding is associated with the upregulation of CDKI and $\mathrm{Kip} 1 / \mathrm{p} 27$, and the downregulation of cyclin B1 and Cdk1. Pre-treatment with the eNOS inhibitor, L-NAME, or the SIRT1 inhibitor, EX527, attenuated Kip1/p27 expression, and increased cyclin B1 levels (Fig. 7). These results indicated that the effect of polydatin on VSMC proliferation is mediated by eNOS and SIRT1.
The c-myc is an important oncogene that regulates cell growth. Activation of c-myc promotes the proliferation of many cells, including VSMCs (35). In our study, c-myc expression was significantly increased by $\mathrm{H}_{2} \mathrm{O}_{2}$ and this response was inhibited by polydatin.

Resveratrol is a trihydroxy stilbene that is effective against oxidative stress and in the treatment of cardiovascular diseases (36). Numerous stilbene analogues have been developed based on the structure of resveratrol. A previous study 
$\mathbf{A}$

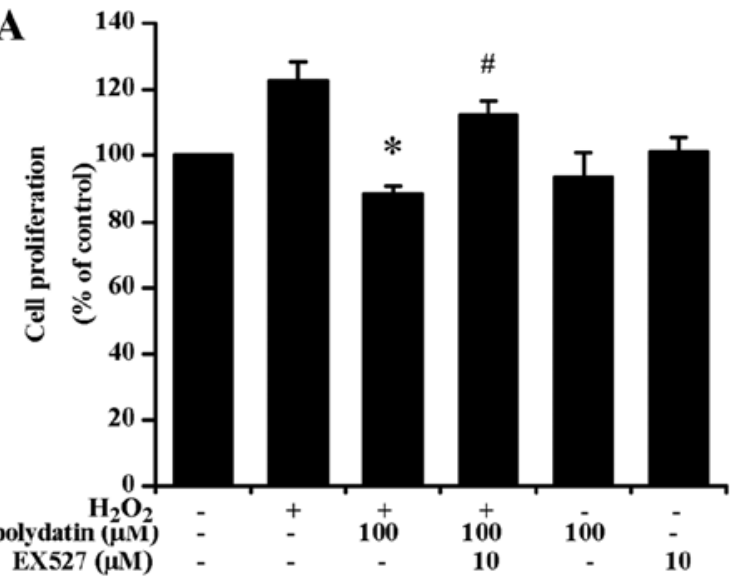

C

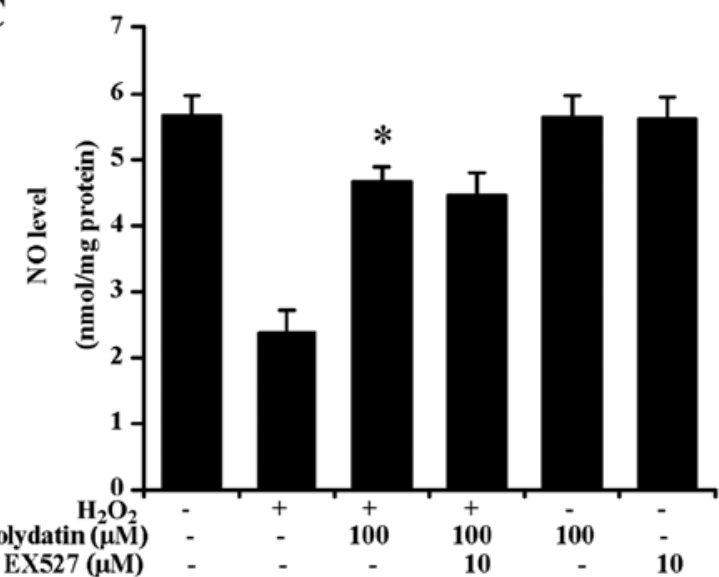

B

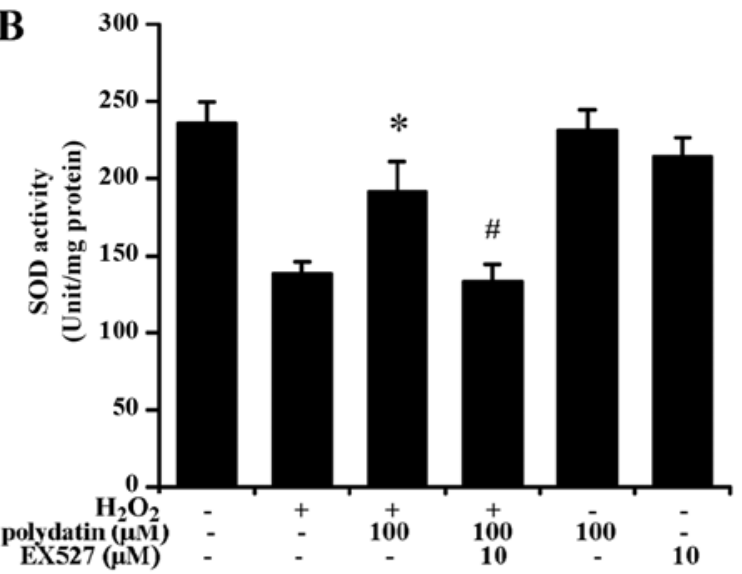

D

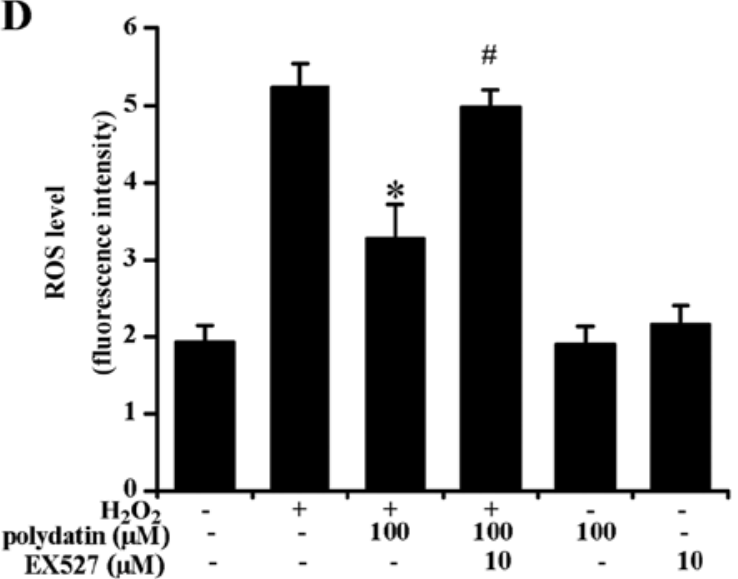

E
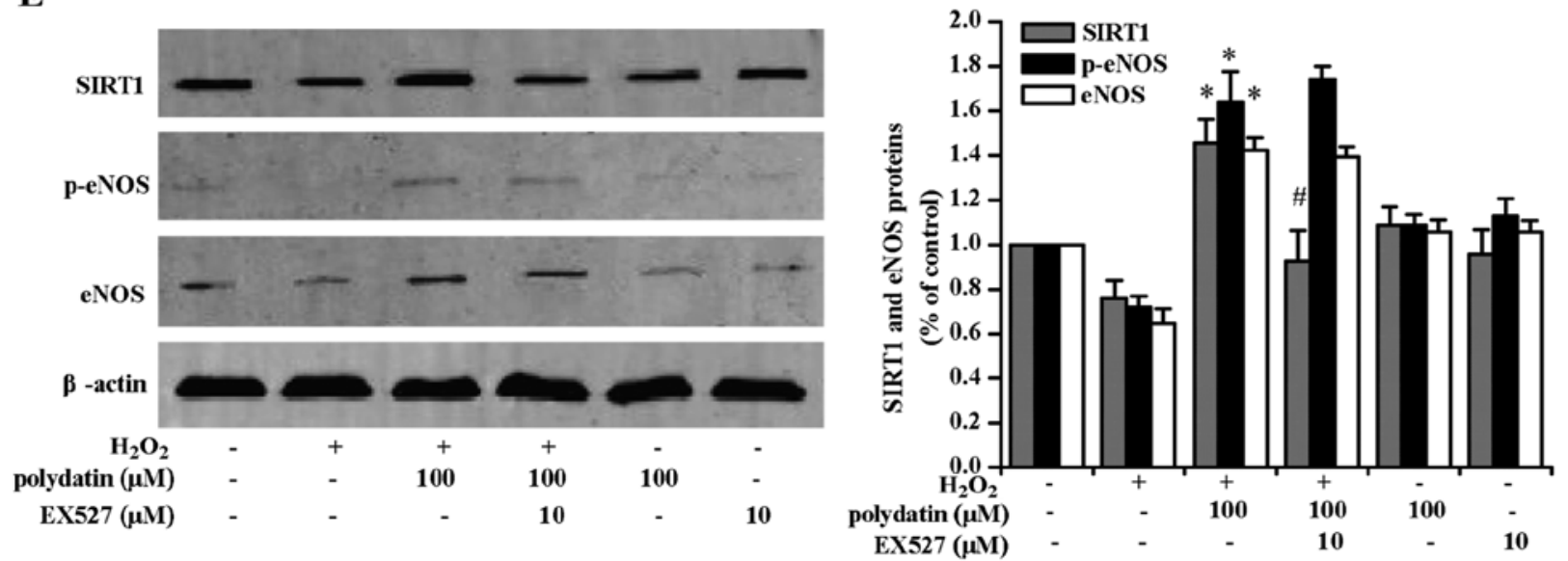

Figure 6. Effects of EX527 in vascular smooth muscle cells (VSMCs). (A) Meaurement of cell proliferation in VSMCs treated with EX527. (B) Measurement of SOD activity in different groups. (C) Measurement of NO levels in different groups. (D) Measurement of ROS levels in different groups. (E) Quantification of silent information regulator 1 (SIRT1), p-eNOS and eNOS protein expression in different groups detected by western blot analysis. Data are presented as the means \pm SD of three independent experiments. ${ }^{*} \mathrm{P}<0.05$ vs. $\mathrm{H}_{2} \mathrm{O}_{2}$-treated group alone; ${ }^{*} \mathrm{P}<0.05$ vs. $\mathrm{H}_{2} \mathrm{O}_{2}$ combined with $100 \mu \mathrm{M}$ polydatin treatment group.

indicated that polydatin and resveratrol possess scavenging activity against hydroxyl radicals in vitro (36). To evaluate the effect of polydatin on $\mathrm{H}_{2} \mathrm{O}_{2}$-treated VSMCs, we assessed NO, SOD, and ROS levels. In our experiments, the levels of $\mathrm{NO}$ and SOD were significantly increased following treatment with 50 and $100 \mu \mathrm{M}$ polydatin, with a concomitant decrease in ROS levels. The results suggested that polydatin plays an anti-oxidant role by increasing the cellular oxidative tolerance to extracellular oxidative environmental change, as well as by eliminating ROS caused by oxidative stress in VSMCs.

eNOS regulates VSMC proliferation (37). Several protein kinases, including Akt/PI3K and AMPK, activated eNOS by phosphorylating Ser1177 in response to various stimuli $(38,39)$. A previous study showed that resveratrol increased eNOS mRNA and protein expression levels and promoted NO production in endothelial cells (40). Resveratrol has been 

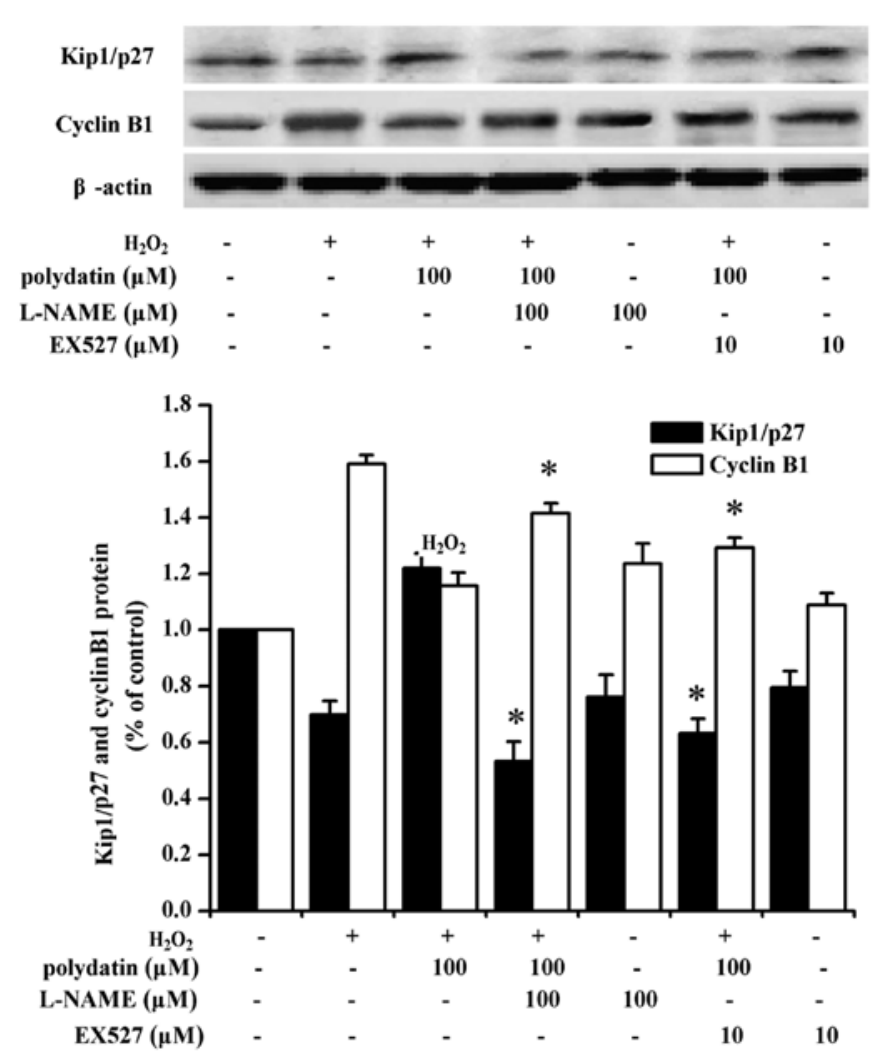

Figure 7. Effects of L-NAME and EX527 on polydatin-mediated cyclin B1 and Kip1/p27 protein expression in vascular smooth muscle cells (VSMCs). The cells were treated with L-NAME $(100 \mu \mathrm{M})$ or EX527 $(10 \mu \mathrm{M})$ for $2 \mathrm{~h}$, and then treated with polydatin and $\mathrm{H}_{2} \mathrm{O}_{2}$ for $24 \mathrm{~h}$. The total cellular protein extracts were prepared and adjusted for western blot analysis with appropriate dilutions of specific antibodies for cyclin B1, Kip1/p27 and $\beta$-actin. Data are presented as the means $\pm \mathrm{SD}(\mathrm{n}=3) .{ }^{*} \mathrm{P}<0.05$ vs. $\mathrm{H}_{2} \mathrm{O}_{2}$ combined with $100 \mu \mathrm{M}$ polydatin treatment group.

shown to inhibit rat aortic VSMC proliferation through estrogen receptor-dependent NO production (41). The present study demonstrated that the inhibition of eNOS by $\mathrm{H}_{2} \mathrm{O}_{2}$ was accompanied by a decreasing $\mathrm{NO}$ expression level. Although eNOS/NO expression by polydatin was not equivalent to the restoration of VSMC function in the normal control group in the present study. Thus, polydatin may attenuate VSMC proliferation. In our experiments, L-NAME, a reversible eNOS inhibitor, downregulated the expression of eNOS, SIRT1 and Kip1/p27, with the concomitant upregulation of cyclin B1 protein expression. We hypothesized that L-NAME reversed the inhibitory effects of polydatin on cell proliferation by inhibiting eNOS expression.

SIRT1 regulates many pathways for nutrient bioavailability, cellular energy status and various receptor signaling pathways. SIRT1 has been proven to inhibit oxidative stress (42), interact with eNOS to improve vascular function and retard endothelial senescence (43). Resveratrol induced VSMC differentiation by stimulating SIRT1 and AMPK (44). SIRT1 was regulated by NO when shuttled between the nucleus and cytosol, upregulated ROS scavengers, Mn-SOD and catalase, and catabolized toxic $\mathrm{H}_{2} \mathrm{O}_{2}$, which in turn was detoxified to water (45). SIRT1 is a crucial regulator of radical scavengers and transcriptional activation, and inhibits inflammatory expression via induction of eNOS $(46,47)$. Thus, the SIRT1-eNOS/NO signaling pathway may be regarded as a potential target against atherosclerosis (48). In the present study, the expression of SIRT1 protein in VSMCs was significantly induced by polydatin. The peak effect on SIRT1 expression at $100 \mu \mathrm{M}$ polydatin positively correlated with eNOS expression, suggesting that SIRT1 maybe involved in NO synthesis.

EX527, a specific inhibitor of SIRT1, did not affect the expression of eNOS in VSMCs. We hypothesize that SIRT1 may act as antioxidant regulator by activating upstream eNOS/NO in VSMCs. Taken together with the findings regarding cell cycle-related proteins, results of the present study suggest that SIRT1 functions as a vital regulator of the anti-proliferative effect of polydatin in VSMCs.

There are some limitations to our study. Firstly, it remains undetermined whether polydatin and resveratrol are capable of enhancing the activation of the eNOS/SIRT1 pathway in VSMCs. Secondly, the $\mathrm{H}_{2} \mathrm{O}_{2}$ model does not faithfully represent the in vivo oxidative damage microenvironment. Thirdly, the present study did not include the AMPK/eNOS pathway, which is apparently important for cell proliferation.

In conclusion, our study has demonstrated that polydatin improves oxidative stress-related changes by increasing SOD levels, ameliorating the level of ROS, inhibiting cell proliferation, upregulating eNOS/NO-SIRT1 expression during $\mathrm{H}_{2} \mathrm{O}_{2}$-induced oxidative damage in VSMCs. The present findings may contribute to the development of strategies for the prevention and treatment of oxidative lesions in the vasculature by targeting the eNOS/NO-SIRT1 pathway.

\section{Acknowledgements}

This study was supported by grants from the Science and Technology Item of Guangdong Province (2010B031500013) and the National Basic Research Program of China (2007CB507404).

\section{References}

1. Das S and Das DK: Resveratrol: a therapeutic promise for cardiovascular diseases. Recent Patents Cardiovasc Drug Discov 2: 133-138, 2007.

2. Chen H, Tuck T, Ji X, Zhou X, Kelly G, Cuerrier A and Zhang J: Quality assessment of Japanese knotweed (Fallopia japonica) grown on Prince Edward Island as a source of resveratrol. J Agric Food Chem 61: 6383-6392, 2013.

3. Du QH, Peng $\mathrm{C}$ and Zhang H: Polydatin: a review of pharmacology and pharmacokinetics. Pharm Biol 51: 1347-1354, 2013.

4. Chen L, Lan Z, Lin Q, Mi X, He Y, Wei L, Lin Y, Zhang Y and Deng X:Polydatin amelioratesrenal injury by attenuating oxidative stress-related inflammatory responses in fructose-induced urate nephropathic mice. Food Chem Toxicol 52: 28-35, 2013.

5. Wen H, Gao X and Qin J: Probing the anti-aging role of polydatin in Caenorhabditis elegans on a chip. Integr Biol (Camb) 6: 35-43, 2014.

6. Blanc A, Pandey NR and Srivastava AK: Synchronous activation of ERK 1/2, p38mapk and PKB/Akt signaling by $\mathrm{H}_{2} \mathrm{O}_{2}$ in vascular smooth muscle cells: potential involvement in vascular disease (Review). Int J Mol Med 11: 229-234, 2003.

7. Jiang D, Li D and Wu W: Inhibitory effects and mechanisms of luteolin on proliferation and migration of vascular smooth muscle cells. Nutrients 5: 1648-1659, 2013.

8. Lan TH, Huang XQ and Tan HM: Vascular fibrosis in atherosclerosis. Cardiovasc Pathol 22: 401-407, 2013.

9. Jiang X, Liu W, Deng J, Lan L, Xue X, Zhang C, Cai G, Luo X and Liu J: Polydatin protects cardiac function against burn injury by inhibiting sarcoplasmic reticulum $\mathrm{Ca}^{2+}$ leak by reducing oxidative modification of ryanodine receptors. Free Radic Biol Med 60: 292-299, 2013. 
10. Zhao KS, Jin C, Huang X, Liu J, Yan WS, Huang Q and Kan W: The mechanism of polydatin in shock treatment. Clin Hemorheol Microcirc 29: 211-217, 2003.

11. Salminen A, Kaarniranta K and Kauppinen A: Crosstalk between oxidative stress and SIRT1: Impact on the aging process. Int J Mol Sci 14: 3834-3859, 2013.

12. Zhang H, Zhai Z, Wang Y, Zhang J, Wu H, Wang Y, Li C, Li D, Lu L, Wang X, et al: Resveratrol ameliorates ionizing irradiation-induced long-term hematopoietic stem cell injury in mice. Free Radic Biol Med 54: 40-50, 2013.

13. Zarzuelo MJ, López-Sepúlveda R, Sánchez M, Romero M, Gómez-Guzmán M, Ungvary Z, Pérez-Vizcaíno F, Jiménez R and Duarte J: SIRT1 inhibits NADPH oxidase activation and protects endothelial function in the rat aorta: implications for vascular aging. Biochem Pharmacol 85: 1288-1296, 2013.

14. Kao CL, Chen LK, Chang YL, Yung MC, Hsu CC, Chen YC, Lo WL, Chen SJ, Ku HH and Hwang SJ: Resveratrol protects human endothelium from $\mathrm{H}_{2} \mathrm{O}_{2}$-induced oxidative stress and senescence via SirT1 activation. J Atheroscler Thromb 17: 970-979, 2010.

15. Gong X, Ma Y, Ruan Y, Fu G and Wu S: Long-term atorvastatin improves age-related endothelial dysfunction by ameliorating oxidative stress and normalizing eNOS/iNOS imbalance in rat aorta. Exp Gerontol 52: 9-17, 2014.

16. Salabei JK, Cummins TD, Singh M, Jones SP, Bhatnagar A and Hill BG: PDGF-mediated autophagy regulates vascular smooth muscle cell phenotype and resistance to oxidative stress. Biochem J 451: 375-388, 2013.

17. Ni L, Li T, Liu B, Song X, Yang G, Wang L, Miao S and Liu C: The protective effect of $\mathrm{Bcl}-\mathrm{xl}$ overexpression against oxidative stress-induced vascular endothelial cell injury and the role of the Akt/eNOS pathway. Int J Mol Sci 14: 22149-22162, 2013.

18. San Martin A, Foncea R, Laurindo FR, Ebensperger R Griendling KK and Leighton F: Nox1-based NADPH oxidasederived superoxide is required for VSMC activation by advanced glycation end-products. Free Radic Biol Med 42: 1671-1679, 2007.

19. Botden IP, Oeseburg H, Durik M, Leijten FP, Van VarkVan Der Zee LC, Musterd-Bhaggoe UM, Garrelds IM, Seynhaeve AL, Langendonk JG, Sijbrands EJ, et al: Red wine extract protects against oxidative-stress-induced endothelial senescence. Clin Sci (Lond) 123: 499-507, 2012.

20. Wang Q, Zhou H, Gao H, Chen $\mathrm{SH}$, Chu CH, Wilson B and Hong JS: Naloxone inhibits immune cell function by suppressing superoxide production through a direct interaction with gp91 ${ }^{\text {phox }}$ subunit of NADPH oxidase. J Neuroinflammation 9: 32, 2012.

21. Miranda KM, Espey MG and Wink DA: A rapid, simple spectrophotometric method for simultaneous detection of nitrate and nitrite. Nitric Oxide 5: 62-71, 2001.

22. Shi Y, Hou X, Zhang X, Wang Y, Chen Y and Zou J: Inhibition of oxidized-phospholipid-induced vascular smooth muscle cell proliferation by resveratrol is associated with reducing $\mathrm{Cx} 43$ phosphorylation. J Agric Food Chem 61: 10534-10541, 2013.

23. Prasad K: Resveratrol, wine, and atherosclerosis. Int J Angiol 21: 7-18, 2012.

24. Gutiérrez-Pérez A, Cortés-Rojo C, Noriega-Cisneros R, Calderón-Cortés E, Manzo-Avalos S, Clemente-Guerrero M, Godínez-Hernández D, Boldogh I and Saavedra-Molina A: Protective effects of resveratrol on calcium-induced oxidative stress in rat heart mitochondria. J Bioenerg Biomembr 43: 101-107, 2011.

25. Han X, Ling S, Gan W, Sun L, Duan J and Xu JW: 2,3,5,4'-tetrahydroxystilbene-2-O- $\beta$-d-glucoside ameliorates vascular senescence and improves blood flow involving a mechanism of p53 deacetylation. Atherosclerosis 225: 76-82, 2012.

26. Park SJ, Ahmad F, Philp A, Baar K, Williams T, Luo H, Ke H, Rehmann H, Taussig R, Brown AL, et al: Resveratrol ameliorates aging-related metabolic phenotypes by inhibiting cAMP phosphodiesterases. Cell 148: 421-433, 2012.

27. Robb EL and Stuart JA: The stilbenes resveratrol, pterostilbene and piceid affect growth and stress resistance in mammalian cells via a mechanism requiring estrogen receptor beta and the induction of Mn-superoxide dismutase. Phytochemistry 98: 164-173, 2014.

28. Yang H, Baur JA, Chen A, Miller C, Adams JK, Kisielewski A, Howitz KT, Zipkin RE and Sinclair DA: Design and synthesis of compounds that extend yeast replicative lifespan. Aging Cell 6: 35-43, 2007.

29. Szekeres T, Fritzer-Szekeres M, Saiko $P$ and Jäger W: Resveratrol and resveratrol analogues - structure-activity relationship. Pharm Res 27: 1042-1048, 2010.
30. Storniolo CE, Quifer-Rada P, Lamuela-Raventos RM and Moreno JJ: Piceid presents antiproliferative effects in intestinal epithelial Caco-2 cells, effects unrelated to resveratrol release. Food Funct 5: 2137-2144, 2014.

31. Bicknell KA, Surry EL and Brooks G: Targeting the cell cycle machinery for the treatment of cardiovascular disease. J Pharm Pharmacol 55: 571-591, 2003.

32. Bonelli P, Tuccillo FM, Borrelli A, Schiattarella A and Buonaguro FM: CDK/CCN and CDKI alterations for cancer prognosis and therapeutic predictivity. Biomed Res Int 2014: 361020, 2014

33. Wang Z, Fan M, Candas D, Zhang TQ, Qin L, Eldridge A, Wachsmann-Hogiu S, Ahmed KM, Chromy BA, Nantajit D, et al: Cyclin $\mathrm{B} 1 / \mathrm{Cdk} 1$ coordinates mitochondrial respiration for cell-cycle G2/M progression. Dev Cell 29: 217-232, 2014.

34. Payne SR, Zhang S, Tsuchiya K, Moser R, Gurley KE, Longton G, deBoer J and Kemp CJ: p27 ${ }^{\text {kip1 }}$ deficiency impairs G2/M arrest in response to DNA damage, leading to an increase in genetic instability. Mol Cell Biol 28: 258-268, 2008.

35. Wang J, Liu K, Shen L, Wu H and Jing H: Small interfering RNA to c-myc inhibits vein graft restenosis in a rat vein graft model. J Surg Res 169: e85-e91, 2011.

36. Su D, Cheng Y, Liu M, Liu D, Cui H, Zhang B, Zhou S, Yang T and Mei Q: Comparision of piceid and resveratrol in antioxidation and antiproliferation activities in vitro. PLoS One 8: e54505, 2013

37. Huang J, Li LS, Yang DL, Gong QH, Deng J and Huang XN: Inhibitory effect of ginsenoside Rg1 on vascular smooth muscle cell proliferation induced by PDGF-BB is involved in nitric oxide formation. Evid Based Complement Alternat Med 2012: 314395, 2012.

38. Gonon AT, Widegren U, Bulhak A, Salehzadeh F, Persson J, Sjöquist PO and Pernow J: Adiponectin protects against myocardial ischaemia-reperfusion injury via AMP-activated protein kinase, Akt, and nitric oxide. Cardiovasc Res 78: 116-122, 2008.

39. Trott DW, Luttrell MJ, Seawright JW and Woodman CR: Aging impairs PI3K/Akt signaling and NO-mediated dilation in soleus muscle feed arteries. Eur J Appl Physiol 113: 2039-2046, 2013.

40. Takahashi S and Nakashima Y: Repeated and long-term treatment with physiological concentrations of resveratrol promotes NO production in vascular endothelial cells. Br J Nutr 107: 774-780, 2012.

41. Ekshyyan VP, Hebert VY, Khandelwal A and Dugas TR: Resveratrol inhibits rat aortic vascular smooth muscle cell proliferation via estrogen receptor dependent nitric oxide production. J Cardiovasc Pharmacol 50: 83-93, 2007.

42. Hori YS, Kuno A, Hosoda R and Horio Y: Regulation of FOXOs and p53 by SIRT1 modulators under oxidative stress. PLoS One 8: e73875, 2013.

43. Potente M and Dimmeler S: NO targets SIRT1: A novel signaling network in endothelial senescence. Arterioscler Thromb Vasc Biol 28: 1577-1579, 2008.

44. Thompson AM, Martin KA and Rzucidlo EM: Resveratrol induces vascular smooth muscle cell differentiation through stimulation of SirT1 and AMPK. PLoS One 9: e85495, 2014.

45. Tanno M, Kuno A, Horio Y and Miura T: Emerging beneficial roles of sirtuins in heart failure. Basic Res Cardiol 107: 273, 2012.

46. Xia N, Strand S, Schlufter F, Siuda D, Reifenberg G, Kleinert H, Förstermann U and Li H: Role of SIRT1 and FOXO factors in eNOS transcriptional activation by resveratrol. Nitric Oxide 32: 29-35, 2013.

47. Takizawa Y, Kosuge Y, Awaji H, Tamura E, Takai A, Yanai T, Yamamoto R, Kokame K, Miyata T, Nakata R and Inoue H: Up-regulation of endothelial nitric oxide synthase (eNOS), silent mating type information regulation 2 homologue 1 (SIRT1) and autophagy-related genes by repeated treatments with resveratrol in human umbilical vein endothelial cells. Br J Nutr 110: 2150-2155, 2013

48. Ota H, Eto M, Ogawa S, Iijima K, Akishita M and Ouchi Y: SIRT1/eNOS axis as a potential target against vascular senescence, dysfunction and atherosclerosis. J Atheroscler Thromb 17: 431-435, 2010. 